\title{
Music Technology and the Hip Hop Beat Making Tradition: A History and Typology of Equipment for Music Therapy
}

\author{
Alexander Hew Dale Crooke ${ }^{1 *}$ \\ 1 University of Melbourne, Australlia \\ *crookea@unimelb.edu.au \\ Received: 24 March 2018 Accepted: 18 June 2018 Published: 1 July 2018 \\ Editor: Michael Viega Reviewer: Michael Zanders
}

\begin{abstract}
This article contextualises music technology within the Hip Hop tradition of beat making. While literature exploring music technology in music therapy has proliferated in recent years, much of this has focused on the "assistive" function of technology, where it is used to facilitate music making for clients who have limited access to playing acoustic - or non-tech-based - instruments. This paper argues for an alternate lens that positions music technology within the tradition of beat making and that this is a musicing practice of value in its own right. To do so, a brief historical account of the beat making tradition is provided, which locates its origins within Hip Hop culture and acknowledges the evolution of the myriad beat-based genres that have and continue to emerge around music technology. A basic typology of beat making equipment is then provided to foster greater understanding of these technologies as instruments in their own right and their role in shaping contemporary music. To account for the rapid innovation in this area, the typology focuses on pieces with historical significance and the primary functions that remain the building blocks of composition and performance in beat making to this day. Brief accounts of how these instruments can and are integrated into therapeutic practice are also provided. It is acknowledged that this paper itself represents only one, brief account of beat making traditions and instruments. Yet, it is hoped it will promote understanding of their significance and serve as a useful reference in helping practitioners consider how these instruments may enrich practice. It is argued that such consideration is not only useful, but critical for reasons of cultural sustainability, and ensuring the relevance of music therapy practice in the 21st Century.
\end{abstract}

\section{Introduction}

\section{Music Technology in Music Therapy}

While many authors in music therapy agree that music technology remains markedly under-represented in music therapy education, training and practice (Crowe \& Rio, 2004; Hahna, Hadley, Miller, \& Bonaventura, 2012; Magee \& Burland, 2008; Ramsey, 2014), there is a history of scholarly literature which has sought to describe and advocate its benefits in this space. Authors such as Krout and Mason (1988) and Nagler and Lee (1987) have been publishing practice recommendations since the late 1980s, while 
the journal, Music Therapy Perspectives, ran a dedicated column during the 1990s. In more recent years, however, there has been a notable increase in publications which have explored technology in music therapy from a variety of perspectives. These include several surveys of practice (Hahna et al., 2012; Magee, 2006), accounts of use with different client groups (Magee, 2014; Roberts, 2006), and papers which offer different equipment typologies and guides for practice (Knight \& Krout, 2016; Knight \& Lagasse, 2012; Magee \& Burland, 2008).

While the growth of literature in this space is promising, authors continue to note that there remains a paucity of opportunities and dedicated materials for practicing and training music therapists to learn skills in this area (Knight \& Krout, 2016; Ramsey, 2014). Potential explanations for this this continued lack of practical support can be found in several studies which have reported on music therapists' use of and attitudes towards music technology in therapeutic practice. Magee and Burland (2008) highlighted a perception among research participants that music technology is less aesthetically appealing and does not offer the multisensory experience offered by acoustic instruments. Together, these were considered to provide an inferior therapeutic experience. Participants also suggested music technology mitigates requirements of musical skill, thus creating unrealistic expectations of musicianship and potential for unnecessarily complex and overstimulating music. Hahna et al. (2012) also found a number of music therapists preferred acoustic instruments, some again citing sensory issues, while others suggested that music technology interferes with the therapeutic relationship. The authors further reported a more judgemental position among some participants, "that music technology is limited in terms of musicality [and that] based upon these concerns, it seems reasonable to extrapolate that some music therapists see digital music as a lesser form of music, or as 'not' music at all." (Hahna et al., 2012, p. 462). They suggested a general lack of understanding among music therapists of how technology can be used in music making - particularly in practice settings - and advocated the need for more research, education, and training in this area.

The perception music technology affords music making opportunities that are inauthentic or inferior to acoustic ${ }^{1}$ instruments can also be gleaned from a critical reading of the literature. The most visible rationale in existing scholarship for working with music technology is that it can augment the musical experiences of clients who cannot fully access acoustic instruments. Examples include affording music making opportunities for older adults (Engelbrecht \& Shoemark, 2015; Weissberger, 2014) and clients with mental and physical disabilities or impairments (Knight \& Krout, 2016; Kubicek, Martino, \& Zigo, 2011; Martino, 2014). This focus aligns with findings from both Magee (2006) and Hahna et al. (2012) that clinical applications of music technology tend to target clients with developmental or physical disabilities. While there is no doubt such applications represent benefits that are both important and unique to music technology, the degree in which discourse has focused on this area can again be seen to position it as a substandard practice - one that is only relevant when "real" music making with acoustic instruments is not feasible.

Together, these points suggest a position within some sections of the music therapy community that technology-based musicing - to use Ansdell's (2004) definition of the acts and affordances of musicianship - is an inferior or lesser practice in areas that include (but perceivably not limited to) aesthetics, skill, musicality, and therapeutic value. Yet, these perceptions seem oddly out of step with contemporary practice. For example, while reporting resistance among some cohorts, Hahna et al.'s (2012) study suggested that, overall, the use of music technology in music therapists' daily practice is common and increasing (despite the continued lack of training). Edited collections such as Music Technology in Therapeutic and Health Settings (Magee, 2014) also demonstrate the breadth of use among practice today. 


\section{Music Technology, Contemporary Music, and Global Culture}

The idea that music technology remains less relevant than acoustic-only music making in therapy appears most dissonant in the context of contemporary music cultures. For many, technology has not only played an important role in music over at least the last 40 years, it has both defined and made it possible (Holmes, 2012; Taylor, 2014). As Théberge (2001) put it "Any discussion of the role of technology in popular music should begin with a simple premise: without electronic technology, popular music in the twenty-first century is unthinkable" (p. 3). Indeed, the use of technology is ubiquitous in the contemporary music industry, and while some have focused on its role in recording, post-production, and dissemination (Taylor, 2014), its influence extends much further. Technology has become increasingly central to composition, performance, and instruments themselves. Théberge (2001) argued, electronic instruments such as drum machines and synthesisers have not only defined the sound but also the overall aesthetics of contemporary pop music. Yet, as important as the technology itself are the communities that have embraced it.

Early adopters of technology in music practice are responsible for much of what currently enriches our airwaves, streaming sites, and general sonic and cultural vocabulary. From the methods that top pop producers use to create countless hits to an abundance of global youth cultures, the cultural and artistic labour of these communities has had a profound impact on our world. Working outside of accepted canons of musicianship, these communities have, and continue to, blur lines between "machine" and "musical instrument" through a process of trial and error, innovation and dedication (Neill, 2002; Schloss, 2014). This labour has led to the most influential practices, genres and sounds of our time. These communities have created musical cultures with their own history, standards of practice, lore, virtuosos, competitions, and awards.

Yet, these communities have often existed on the periphery of mainstream society. Like innovation in acoustic musicianship through jazz, rock, punk, and funk, most electronic music traditions started within oppressed communities (Buckland, 2002; Said, 2016). Their current iterations continue to speak to oppression, while simultaneously representing the most profitable and listened to genres to ever exist, and existing as fundamental to the collective identity of younger generations globally (Bloustien \& Peters, 2011).

Thus, devaluing technology, as well as the music, communities, and cultures that centre it, seems counterintuitive to the practice of music therapy on several levels. Most obviously, it suggests being "out of touch" with what constitutes music in our current world. It also hazards a disconnect to younger generations. Lastly, it risks perpetuating dominant narratives around musical excellence and cultural elitism, which serve to further marginalise the communities and cultures to whom music technology is more than an "assistive" device.

\section{Shifting the Narrative}

This article offers an alternate perspective; one that sees music technology as a valid and important tool for musical participation, with the skill and aesthetic value comparable to acoustic instruments. It does so by giving an account of the tradition of "beat making," a highly skilled, yet accessible musical practice. This account is located here within the culture of Hip Hop - which was created and developed by urbanbased African American and Afro-Latino communities the US (Rose, 1994) and which became a way to resist oppression, foster community, and promote self-empowerment in these communities (Chang, 2007). Similar narratives exist for other oppressed communities that have also embraced music technology (for evolution of electronic music and the queer scene, see Brewster \& Broughton, 2006; Buckland, 2002), yet arguably the Hip Hop ${ }^{2}$ community's use of technology has made the most profound impact on contemporary music practice. This includes pioneering and popularising the practices central to the myriad beat-based cultures and genres that have followed. 
Music therapy authors continue to make compelling arguments for why music technology should be included in both pre-professional and ongoing music therapy training (Crowe \& Rio, 2004; Hahna et al., 2012; Magee, 2014). It is argued here that not only does this need continue - and is steadily growing in importance - such training should also attend to the social and cultural contexts of music making technology. The following account offers a starting point.

\section{Beat Making}

\section{Hip Hop Roots}

The term which best encompasses the multitude of genres and sub-genres that centre music technology is "beat making." This musical tradition has its roots in the early development of Hip Hop culture in New York throughout the 1970s and early 80s. Simply put, its emergence can be associated with the process in which Hip Hop music evolved from the DJ's turntables to the (often home) studio. By the late 1970s Hip Hop DJs were playing the percussion-heavy "breaks" from disco, funk and other records back and forth between two turntables to loop and extend the most danceable part of the songs (Chang, 2007). The introduction of electronic drum machines enabled artists to compose their own looped drum patterns, while the advent of semi-affordable digital samplers allowed them to create poly-rhythms through the layering of a variety of sampled soundbites (Said, 2016). These devices, and others that followed, have come to define the musical elements of Hip Hop culture, along with a multitude of other genres. Those who use these devices have become known as beat makers, or sometimes producers (Schloss, 2014). To borrow from Said (2016), this article will refer to these devices using the term EMPI "an acronym (pronounced: em-pee) that stands for Electronic Music Production Instrument" (2016, p. xx).

The uniqueness of beat making culture and tradition is recognisable in two important ways. First, while other popular music cultures or genres were incorporating EMPIs around this time (think synthesizers in metal, as well as progressive-, psychedelic-, and Kraut-rock), Hip Hop was (arguably) the first genre to centre music technology as the primary tool for performance and composition ${ }^{3}$. This has led to a distinct musical tradition and practice, with its own lore, traditions, and conventions (Said, 2016), as well as sophisticated aesthetics, with die-hard purists and a swath of associated offshoots and sub-cultures (Schloss, 2014). Secondly, and most importantly, Hip Hop is an African-American culture (Rose, 1994). While developed in the West, it emerged from Afro-diasporic communities, and due to the focus on poly-rhythms, call and response, and non-linear (i.e. looping) time structure, is widely considered an Afro-centric rather than Euro-centric music tradition (Keyes, 1996). Hein (2018) went as far as saying it is "even more Afrological than jazz, eschewing harmony and orchestral instruments entirely" (para.5). Thus, as Schloss (2014) argued, while beat makers in the Hip Hop community have long been remarkably multicultural, "all producers - regardless of race - make African American hip-hop [sic]" (p. 9).

According to digital downloads and streaming figures, Hip Hop is now the most popular music genre in the world (Hillyard, 2015). Yet, the tradition of beat making has remained largely absent from conservatories. Scholars have argued this relates both to the fact that its practices challenge the dominant narrative of Western musical excellence (Hein, 2018; Williams, 2011), and because it is a Black artform (Koza, 2009; Perry, 2004). Both are said to have contributed to its positioning as a redundant or inferior artistic practice (both culturally and technically) and its subsequent exclusion from musical curriculums (Gustafson, 2008). Nevertheless, as participants in Schloss' (2014) ethnographic study showed, to become a respected beat maker requires years of dedicated learning and skill development, and standards within the community can be uncompromising. As Said (2016) wrote, it "is an art-craft that requires serious study and long hours of practice" (p. 1) to master the complex musical conventions and technical equipment, and (despite a growing number of industry-focused courses) perhaps 
all the more remarkable in that it remains a craft that preferences, and arguably relies on, a "self-taught ideology."

\section{The Diversification of Beat Making Cultures}

Beat making culture is also significant in the impact it has had on other forms of music making. Along with its growing ubiquity among almost all forms mainstream pop music, the Hip Hop tradition of beat making was instrumental in the rise of innumerable associated genres and subgenres. While providing a comprehensive account of this diversification is neither the focus of this article, nor within its scope, it is possible to chart a rough course over the last 40 years.

Variation began with several early styles that grew around both Hip Hop culture and the use of early EMPIs. This included electro-funk (later shortened to electro), a style of Hip Hop that centred the electronic sound of early drum machines and synthesisers rather than the more organic sound of record samples. Fink (2005) cited Hip Hop pioneer, Afrika Bambaataa's claim that electro quickly spawned "at least six genres of dance music" (p. 343), including Miami Bass, Latin freestyle, and hip-house. It also formed its own distinct genre throughout the 1980s and has evolved alongside other dance music styles into the current decade with many of its own electro-centric subgenres, including electro-dub, electro-breaks (McLeod, 2001), and electro-house (Thompson, 2012). Around the time Afrika Bambaataa was creating electro, house music was emerging in Chicago, techno in Detroit, and garage in New York ${ }^{4}$ : all three influenced by early Hip Hop as well as disco songs like Donna Summer's "I feel Love," and Kraftwerk's album "Trans-Europe Express." As these styles spread to the UK and mainland Europe throughout the early 1980s, a number of genres grew from their mix with local dub and ragga styles (themselves imports from Jamaica's Reggae and Dancehall scene). This included hardcore, acid techno, gabba, trance, jungle, and later, drum and bass (McLeod, 2001).

The links between Hip Hop and later styles such as jungle and drum and bass (which are widely considered UK artforms) indicate the enduring influence of Hip Hop beat making in this context. While considered distinct from Hip Hop, both jungle and early drum and bass also focused on using the "breaks" favoured by early Hip Hop DJ's (Brabazon, 2012) and used the same sampling techniques (and often the same samples) to create their music (Schloss, 2014). They also involved MC's (or rappers), and members of both Hip Hop (Alim, 2008; Speers, 2017) and drum and bass (Kreems \& Junaini, 2016) cultures often refer to each other as "heads."

These early scenes gave birth to global rave culture, and copious ensuing genres and subgenres - a diversity that formed along musical and political lines, and arguably unparalleled in any other musical tradition (McLeod, 2001) - which are often grouped today under the umbrella term electronic dance music (EDM). Artists such as Fatboy Slim, The Chemical Brothers, and Daft Punk brought dance music out of the clubs and warehouses onto mainstream radio and rock arenas throughout the 1990s, paving the way for the superstar DJs of today that continue to sell out stadiums (think Tiësto, David Guetta, and Skrillex). Yet, while DJs have become known as the figureheads of these movements, it is the beat makers ${ }^{5}$ who continue to transform and push things forward:

Innovative pop electronic composers use steady pulse, loop-based structures and 4/4 time as a vehicle for a wide range of compositional ideas and innovations. Shifts of tempo, subdivision, sonic manipulation and complex quantization structures are making beat science the new jazz of the 21 st century. Much in the same way that jazz soloists listened to each other and incorporated each other's licks into their own solos, beat makers around the world listen and learn from each other through the underground network of DJs, 12-inch white-label vinyl records, mp3s, CDRs and the Internet. The artistry of pushing a new style of beat forward is highly refined; at any given time there are many styles being practiced and developed along with new hybrids forming and new genres constantly emerging. (Neill, 2002, p. 4) 
These hybrid styles continue to cycle and interact with Hip Hop culture. Styles such as dubstep (considered a form of dance music) and trap (a more contemporary iteration of Hip Hop) coalesce around similar tempos and beat structures, as well as the continued use of early drum machine sounds, digital sampling, and beat making techniques from the Hip Hop tradition (Marr, 2016). While such genres maintain dedicated underground scenes, they are also widely accepted by, and very much in the fabric of, current mainstream pop music.

While this account necessarily glosses over the nuances, intricacies, and debates around these histories ${ }^{6}$, it is offered here to acknowledge both the roots of beat making cultures and the dedication of those who practice them ${ }^{7}$. Such acknowledgement also aims to highlight the need for adopting a stance of cultural humility when engaging in these cultures, in the same way scholars advocate when engaging any culture through music therapy practice (Hadley \& Norris, 2016; Hiller \& Gardstrom, 2018; Kim \& Whitehead-Pleaux, 2015). Recognition of this history and context is also critical to address the history of cultural appropriation in this space (Rodriquez, 2006) and position music therapists as social actors who can use their positions to disrupt dominant narratives linked to oppression (Scrine, 2016).

\section{A Typology of Beat Making Equipment}

The range and number of EMPIs available today are as almost diverse as the musical cultures that use them. Yet, it is possible to identify a typology of devices, instruments and functions that have played key roles in defining different musical traditions and also remain the building blocks of contemporary EMPIs. The typology offered here is but one possible way to conceptualise these instruments, yet differs in important ways from those provided by authors such as Knight and Krout (2016). It aims to identify the key tools of beat making traditions and their functions, to enable an accessible guide for therapists wanting to integrate beat making and the associated contemporary music cultures into their practice.

\section{The Turntable}

While it might not be considered by many as an EMPI, the turntable (or record player) has played an important role in beat making history and remains central to beat making cultures. Turntables were the first piece of technology used by the early Hip Hop, house and techno DJs to manipulate sounds, particularly for looping "breaks." Their role as a live performance instrument was extended by the art of scratching, a technique credited to Grand Wizard Theodore of the Bronx (Chang, 2007). By pushing the record back and forth on the turntable with their fingers, DJs create a chirp-like sound that can be used to form percussive, rhythmic, and even melodic phrases. Using a sound mixer's "crossfader" - literally, a volume-style fader invented by pioneering Hip Hop DJ, Grandmaster Flash, to mix between two sound sources (D'Errico, 2016) DJs can also "cut" this sound in and out to add more rhythmic complexity. This grew into the tradition of "turntablism", within Hip Hop, where DJs use a mixer and two or more turntables to create complex performance routines (Thompson, 2012).

As D'Errico (2016) maintained, the act of DJing with two turntables and a mixer not only "played a fundamental role in shaping the music production and performance practices of hip-hop [sic], as well as cultural aesthetics more broadly" (p. 132), it has also been critical for preserving the culture. Foundational to all beat-based cultures, the appeal of DJing with vinyl remains strong, and is still preferred over other DJing formats by purists. As Katz (2012) argued,

Probably the most important reason for its success is its physical immediacy. The hand rests comfortably on the grooved, slightly tacky surface of the record. That tactility is enormously important to DJs, who often wax eloquent about the inimitable feel of vinyl. Pushing a record underneath a turntable needle, transforming the music held within its grooves, one has a sense of touching sound. Scratching a record isn't much different from playing traditional instruments that use friction to create their sounds. (p. 64) 
Turntables are now often replaced with technology such as CDJs, or "controllers," that use platters to represent turntable surfaces and allow DJs to manipulate music on CDs or digital files such as MP3s in the same way as one manipulates records. Some newer controllers are even more stripped back, using buttons to trigger a song, or samples, usually at a pre-defined spot, or "cue point," in the song.

While using traditional turntable and mixer setups in music therapy settings has been reported as challenging, due to time required to build basic skills and familiarity with equipment (Crooke \& McFerran, 2018), controller-based DJing may prove more accessible for clients. This could include a client using cue-points to trigger their favourite parts of one or more songs or creating rhythmic contributions by simulated scratch platters in improvisation. As MacDonald and Viega (2012) reported, simulated scratching technology can also be used in song writing to "embellish [songs] in an infinite number of ways" (p. 158).

\section{The Drum Machine Step Sequencer}

The Roland Corporation's release of the TR-808 drum machine in 1980 marked a turning point in beat making history. Functionally, this EMPI allows a beat maker to program a rhythmic loop of 16 "steps," usually making a one-bar pattern of 16th notes (depending on the settings). For each of these 16 steps, a beat maker can input a drum sound or "hit" to make up a pattern. This could be repeated for up to 12 drum sounds, or "instruments," for a single pattern to create multilayered rhythms that can be played on endless loop.

Originally created as an alternative to an acoustic drummer, the TR- 808 failed commercially and production ceased in 1983. However, Hip Hop artists took to the synthetic sounds (particularly the low-frequency sub-bass) and the ability to extend loops, and it became the community's tool of choice (Rose, 1994). Beyond Hip Hop, it has also had a profound and lasting impact on popular music. It now has cult-status, and its original sounds remain in wide usage today (Leight, 2016).

The 808 also represents a lasting format in beat making. The 16-step sequencer layout has been recreated on many drum machines since. This includes the Roland TR-909 (created in 1983, and credited for the "sound" of techno) that added MIDI connections, allowing beat makers to connect it with other EMPIs with onboard sequencers, and play them in time together. This became a default format for many electronic music performers, enabling them to play live sets by linking different instruments together via MIDI, including synthesisers and samplers, to play different parts of a song. This step-sequencer format has remained a mainstay in the EMPI world and can be found on numerous hardware, software, and MIDI-controller devices today.

Lightstone (2012) explained how sequenced drum machines could be particularly useful for creating groove-based musical experiences which foster comfort, movement, enjoyment, and social acceptance in music therapy. Drawing on his experience facilitating Hip Hop sessions with youth, he contended, "the familiar musical framework and timbres [a drum machine] provides are potentially liberating, because the comfort and familiarity it provides allows rhythmically intense, life-affirming and expressive musicing" (p. 48). MacDonald and Viega (2012) described how programming or using preprogramed beats in a drum machine was easy, accessible, and appealing for young people in their study and offered an alternative to acoustic drums that "had the effect of driving the group apart" (p.157). Such programmed beats can either be used in song writing, or as a foundation over which to improvise.

\section{The Synthesiser}

The first synthesiser (or "synth") can be traced back to electrical engineer, Alisha Gray, who in 1876 (one year before Edison created the phonograph) created the first single note oscillator (Burgess, 2014). Later iterations were in popular usage by the 1970s and are so widely available little explanation is needed here. What is of note is that they are a mainstay in many beat making cultures, many of which use synths exclu- 
sively to create all sounds used in compositions and performance (often including percussion), excluding acoustic instruments all together. Certain synths have also taken on the role of certain instruments. For example, the Roland TB-303 synth has been called the "electric guitar" of dance music by Australian producer and scholar, Haberfield (AKA Honeysmack), given its distinctive sound, and the depth and breadth of its influence in dance music (Dalgarno, 2017). Other synths are known for their bass or "lead" sounds and beat makers and producers have become famous for the way they sculpt or shape their own unique sounds. This has led to a large range of sophisticated synths that can play an arguably limitless range of sounds, including incredibly realistic reproductions of acoustic instruments, such as strings and brass.

Most physical (or "hardware") synths are played using a keyboard, yet many can also be programmed using an onboard step sequencer similar to that used in the TR-808 and can therefore be linked together using MIDI to play in time with other EMPIs. Some are standalone sound modules and need to be connected to an external control source (i.e. keyboard or MIDI sequencer). While there are many hardware versions still in production, there are thousands of software synths available.

A global culture has also grown specifically around synthesisers. There are many boutique, bespoke, and limited-edition synths. Users can also customise their own synths, or build them from scratch, using a wide array of DIY kits available on the market (Richards, 2013).

As Viega (2014) explained in detail, synthesisers provide clients access to almost innumerable variety of textured sounds. While such sounds could be used in many music therapy approaches, Viega emphasised their value in creating soundscapes, and therapeutic approaches that employ the "ambient mode" of listening.

\section{Sample Pads}

While often controversial for copyright reasons, sampling is a defining feature of many beat making cultures (including Hip Hop and drum and bass,) and is a practice that is often linked to strict rules, ethics, and conventions within these cultures (Said, 2016; Schloss, 2014). The first digital samplers were prohibitively expensive, but when more affordable (although still expensive) samplers such as the E-mu Systems Inc.'s SP-12 (Anderton, 1987) became available, Hip Hop beat makers were able to sample and rearrange sections of their favourite records (as well as TV shows and movies) to make their own compositions (Schloss, 2014).

Arguably, however, the samplers which most defined beat making culture were Akai's MPC (Music Production Center) series. Beat makers could load whatever sounds they liked across their trademark 16 pad layout, playing the samples back in rhythmic fashion with their fingers. This often involved recording segments of vinyl, and "chopping" them up to bite-size samples that could be placed on different pads and then re-pitched, re-arranged, and layered to create original compositions. This became the hallmark of Hip Hop beat making throughout the late 1980s and 1990s, and remains the EMPI of choice for many Hip Hop producers (Said, 2016). It also led to the practice of "finger drumming," where beat makers use their fingers to play entire songs using the pads for both composition and performance.

The ability to "perform" or play an MPC (or similar pad-based EMPIs) like an instrument is significant and widely recognised. Creator, Roger Linn (1994), explicitly acknowledged this in the user manual for the MPC3000: "I like to think of the MPC3000 as the piano or violin of our time, and you as an MPC3000ist" (p. 2). MPC virtuoso, the late J Dilla, embodied this ideal. Credited for "humanising" the MPC, his style of playing and programming beats is not only a benchmark for beat makers, but has also influenced the technique and aesthetic of live drummers and other forms of acoustic musicianship (Stadnicki, 2017).

This "sample pad" layout can be found on many present EMPIs, both in hardware form, and in MIDI controllers connected to computers. This includes MIDI controllers such as Ableton's "Push" interface and Novation's "Launchpad," both of which have 
expanded the 16-pad layout to a 64-pad grid. The sample pad performance/production approach is now used widely across beat making styles, including more dance-orientated genres such as Dubstep (see "Controllers" below for more information on the use of sample pad controllers in production and/or performance).

Sample pads have a wide application in music therapy. Recent research has found the ability to pre-select sounds representative of a wide variety of genres enables clients an accessible way to perform their cultural or musical identities. It also allows therapists to offer diverse sound palates valuable for playing differing feelings or emotions during improvisation (Crooke \& McFerran, 2018). They can also be used in composition to perform and record drum beats and melodic patterns.

\section{Digital Audio Workstations (DAWs)}

As computers became more powerful and affordable throughout the 1980s and 1990s, a number of software solutions became available to beat makers. Most notably, this included the Digital Audio Workstation, or DAW, which evolved to constitute an entire studio on a computer. These enabled beat makers to not only record external instruments and vocals across multiple audio tracks but also to program MIDI sequences to play back both external EMPIs, such as synths and samplers, as well as internal software versions. These software EMPIs became available in a range of VSTs (Virtual Software Technology), that included both instruments as well as effects and mastering tools which could be added to a DAW of choice and enabled beat makers to create complex compositions in their own home studios. For some beat makers, DAWs serve as an EMPI, where beats can be made entirely with the computer using the mouse and computer keyboard.

Apple's Garageband is a common entry-level DAW. More industry-standard DAWs such as Logic Pro, Ableton Live, and Pro Tools are more flexible and commonly used in home and professional studios. The value of DAWs in music therapy practice is well referenced in the literature (Roberts, 2006; Sadovnik, 2014; Weissberger, 2014). Much of this focuses on the acknowledgment that a DAW loaded on a laptop allows practitioners to provide accessible yet reasonably sophisticated song writing and composition opportunities in almost any setting.

\section{Controllers}

Controllers are physical interfaces that (mostly) do not produce any sound themselves but are used to control software or other sound sources. These can be divided into two main categories (although these categories are now often combined in a single piece of equipment): DJ controllers and production/performance controllers. DJ controllers are used to substitute or simulate turntables, where the music is coming from a computer instead of records or CDs. This is linked to the Controllersim culture or movement which emerged in the early 2000s as a response to the growing use of computers, and what D'Errico (2016) called the "button pusher debate," the idea that DJs and beat makers using computers can hide behind a computer and press "play" without actually undertaking any performance. Controllers thus provide DJs using computers a physical piece of equipment which can be connected to their computer via USB-MIDI to manipulate or "perform" the music they are playing.

Rather than specifically simulating the role of a turntable (i.e. mixing pre-recorded songs), production/performance controllers are used to compose beats or perform the actual beats in a live format. Basic examples of production controllers include sample pads which are designed only to control computer software through USB-MIDI connections or even a MIDI-keyboard. Again, this equipment itself does not produce any sound unless connected to another sound source. A performance controller may include these pad or keyboard functions, but rather than just playing a single sound or note, they can be used to "trigger" or "launch" a range of loops and samples - often called "clips" - that can be combined and changed to play the different parts of a song. Most commonly, this is achieved via a grid of buttons or rubber pads (e.g. Ableton 
"Push" or Novation "Launchpad") that are assigned to different clips; by pressing different pads/buttons, the beat maker can play arrangements of a song by triggering its different parts. These controllers often have a range of other buttons knobs and sliders/faders which can be used to adjust the volume or apply effects to different song parts, and can be used to play entire sets.

Given controllers often represent or reproduce hardware devices, they can facilitate many of the therapeutic activities noted above. The ability to trigger or launch clips, however, represents a particular affordance of these EMPIs. Through an improvisational approach, clients are able to perform sophisticated beats by rearranging numerous pre-composed elements (drums, bass, melody, vocal samples) in the moment. The accessibility of this practice allows a client to experience themselves as an accomplished beat maker almost instantly, while the ability to load clips representative of particular genres allows them to engage in performing their culture and identity (Crooke \& McFerran, 2018).

\section{Gesture-based EMPIs}

As the Controllerism movement has progressed, engineers and beat makers have created an increasingly inventive range of controller devices and technologies to capture gesture-based movements (think Theremin with 21st century technology), spawning an innovative DIY controller design culture that is constantly evolving. While many music therapists may be less inclined to design their own instrument, this type of EMPI is relevant to practice in two ways. First, these EMPIs are often designed to minimise the need for traditional musical training, and facilitate almost instant, or at least intuitive, accessibility to musical expression (D'Errico, 2016). Thus, this gear offers accessibility to both clients with little musical background and limited physical or mental capacity, while still maintaining relevance to contemporary music culture. Second, there are a range of gesture-based technologies readily available in commercially available EMPIs.

One of the most common devices used today is the accelerometer, which allows beat makers to change sounds, or alter the character of a sound, by changing the orientation of an object in space (Gopinath \& Stanyek, 2014). For example, tilting a controller forward may make a beat more complex (introducing extra snare and bass drum hits), and tilting it back may decrease this complexity. Tilting the controller left or right could employ a filter effect that takes out the high frequencies, or a delay effect. Perhaps the best known EMPIs to use this technology are the "MIDI Fighter 3D" by DJ TechTools, and the ZOOM "ARC," both of which enable users to map any MIDI function or effect to the different axis of the accelerometer. Most smart phones and tablets are now also equipped with this technology and have music apps which utilise such functions.

Another common gesture-based feature is the X-Y touchpad, which a beat maker can either tap, or drag their finger across to play different sounds or change the nature of a sound. For example, dragging a finger from left to right (along the $\mathrm{X}$ axis) may play the different notes of a scale, while moving the finger from the bottom to the top (along the Y axis) may apply a filter effect to the sound. Perhaps the best-known hardware version of these XY pads are the Korg "Kaoss Pads," however there are several USB-MIDI controller versions available, and again, many smartphone and tablet apps use this function.

\section{"All-in-One" VS Standalone EMPIs}

It is worth noting that some EMPIs have only one task, instrument or function. For example, Roland TR-808-style drum machines, as well as most synthesisers, are designed to create a dedicated part of a song. Like a more traditional acoustic instrument, these can be considered as playing one part in an ensemble.

However, many EMPIs on the market are capable of undertaking a wide range of tasks and creating a whole song. For example, some hardware versions of the Akai MPC and Korg Kaoss Pads, as well as EMPIs such as the Korg Electribe, Roland SP-404, 
and Novation Circuit have the capability to play, record, and arrange melodies and drum parts to form full songs. DAWs are also capable of creating full tracks.

For music therapy practice, the choice of EMPI (or EMPIs) may depend on how the practitioner intends to use it. One may find it more useful to have an "all-in-one" solution that is more portable, and that would be used with individual clients, or to compose songs one part at a time in small groups. Alternatively, having several standalone EMPIs may be more suitable for group work, providing different options for group music making that are dedicated to certain roles (i.e. drum, bass, or melody parts) and have less functions which can distract or overwhelm clients from a musical task or role.

\section{Discussion}

The (necessarily brief) account of the Hip Hop beat making tradition provided in this article intends to offer an alternate view of music technology in the context of music therapy. Specifically, it aims to challenge the narrative of music technology as providing an inferior musical and therapeutic experience, one that's primary value is in "assisting" or compensating for a lack of access to acoustic instruments. By acknowledging the rich and varied musical cultures that have adopted and been informed by music technology, as well as the cultural significance and musicality of electronic instruments, this article argues they be recognised as valuable in their own right - both musically and therapeutically.

Considering the pivotal role beat making practices, instruments and genres play in both contemporary youth and popular cultures, subjugating beat making in music therapy has many contraindications that jar with the ethos and goals of the discipline. From a therapeutic perspective, it has the potential to ignore or devalue the musical identity and preferences of certain clients or client groups and limit their access to musical experiences of value to them. From a more macro perspective, it also has implications for promulgating an elitist perception of music and music making. Maintaining and reinforcing such a position through the discipline of music therapy runs a risk of maintaining oppressive narratives towards certain musical practices, as well as the clients who identify with them.

The subjugation of beat making as a musical practice also has important implications from a social justice perspective. As outlined above, beat making stems from Hip Hop - a culture that not only speaks to numerous marginalised communities around the world, but one that at its core is rooted in the experience of the African diaspora in the US. Positioning the musical practices of Hip Hop and related genres as less-than, plays a role in perpetuating systems of oppression long experienced by these communities.

This article has aimed to foster a different positioning which acknowledges the wider value of music technology. By providing an alternate typology, one that is rooted within the musical traditions and history of beat making, it is hoped that therapists unfamiliar with electronic instruments can build an understanding of their roles, functions, and historical significance. Not only is this typology offered as a practical guide for practitioners to consider how (and which) EMPIs might be utilised in practice, it also aims to acknowledge their cultural significance. As has been eloquently argued by others, such recognition is necessary for the use of any instrument, both to enrich the experience of clients (Gardstrom, 2007) and to respect the cultures and communities from which the instruments or music originate (Hadley \& Norris, 2016). Indeed, such acknowledgment and recognition is considered a core standard of music therapy practice (Gardstrom, 2007; Hiller \& Gardstrom, 2018).

\section{Conclusion}

Music technology, as understood through the lens of the Hip Hop beat making tradition, offers much to the field of music therapy. However, it would seem that to fully actualise this potential, there is a need to revise perceptions that music technology of- 
fers a lesser form of music making. As this article has aimed to convey, beat making has a rich history that is interwoven with some of the most innovative and culturally relevant musical practices of our time. Further, the associated instruments have value that can be seen as equal to their acoustic counterparts, both in their musicality and aesthetic appeal. By building an understanding of the contexts, instruments and significance of beat making, it is argued that music therapy practice is well placed to maintain cultural and therapeutic relevance.

\section{Notes}

1. The distinction between "electronic" and "acoustic" instruments is problematic in these arguments, given the reasonable assumption that electronic keyboards and electric guitars would hold the same cachet as acoustic instruments. Nevertheless, the term acoustic is used in this article to refer to instruments not of the beat making tradition.

2. This capitalisation of Hip Hop aligns with Viega's (2016) discussion on KRS-One's definitions and spellings of the term, where the capitalisation of both H's and no hyphen refers to Hip Hop culture, rather than the commercial (hip-hop) or spiritual (Hiphop) elements of this culture. I have used Hip Hop throughout the article, even when referring to the musical product, to signify its cultural significance beyond commercial value.

3. Compelling counter arguments could be made here regarding Dub (Chang, 2007), House, Garage and Techno (Buckland, 2002) as well as the experimental movement associated with groups such Kraftwerk (Kirn, 2011).

4. Again, these origins are notoriously debated, but these are the most often cited.

5. It must be noted that even from the earliest days, many DJs are beat makers themselves and often used DJing as a way to play their own music at live events.

6. See Holmes (2012) and Kirn (2011) for alternate genealogical histories of contemporary electronic music.

7. Readers are encouraged to access the wide range of detailed accounts available in this space to deepen their own knowledge; whether in the form of academic texts such as Amir Said's (2016) “The BeatTips Manual”, Tricia Rose's (1994) "Black Noise," or the many videos available on streaming services.

\section{References}

Alim, H. S. (2008). Intro: Straight outta Compton, straight aus München; global linguistic flows, identities, and the politics of language in a global Hip Hop nation. In H. S. Alim, A. Ibrahim, \& A. Pennycook (Eds.), Global linguistic flows: Hip hop cultures, youth identities, and the politics of language (pp. 1-24). New York, NY: Routledge.

Anderton, C. (1987). SP-1200 Owners manual. Scotts Valley, CA: E-MU Systems.

Ansdell, G. (2004). Rethinking music and community: Theoretical perspectives in support of community music therapy. In M. Pavlicevic \& G. Ansdell (Eds.), Community Music Therapy (pp. 65-90). London, UK: Jessica Kingsley Publishing.

Bloustien, G., \& Peters, M. (2011). Youth, music and creative cultures: Playing for life. Hampshire, UK: Palgrave Macmillan. https://doi.org/10.1057/9780230342491.

Brabazon, T. (2012). Popular music: Topics, trends \& trajectories. New Delhi, India: SAGE.

Brewster, B., \& Broughton, F. (2006). Last night a DJ saved my life: The history of the disc jockey. London, UK: Headline.

Buckland, F. (2002). Impossible dance: Club culture and queer world-making. Middletown, CT: Wesleyan University Press.

Burgess, R. J. (2014). The history of music production. New York, NY: Oxford University Press.

Chang, J. (2007). Can't stop won't stop: A history of the Hip-Hop generation. New York, NY: Picador. 
Crooke, A. H. D., \& McFerran, K. S. (2018). Improvising using beat making technologies in music therapy with young people: It's all about the resources. Manuscript submitted for publication.

Crowe, B. J., \& Rio, R. (2004). Implications of technology in music therapy practice and research for music therapy education: A review of literature. Journal of Music Therapy, 41, 282-320, https://doi.org/10.1093/jmt/41.4.282.

D'Errico, M. A. (2016). Interface aesthetics: Sound, software, and the ecology of digital audio production. Los Angeles: University of California. Unpublished doctoral dissertation.

Dalgarno, P. (2017). How to make an acid dance track with the Roland TB-303. Retrieved from http://precinct.finearts-music.unimelb.edu.au/2017/09/22/how-to-make-an-aciddance-track-with-the-roland-tb-303/

Engelbrecht, R., \& Shoemark, H. (2015). The acceptability and efficacy of using iPads in music therapy to support wellbeing with older adults: A pilot study. The Australian Journal of Music Therapy, 26, 49-70.

Fink, R. (2005). The story of ORCH5, or, the classical ghost in the hip-hop machine. Popular Music, 24(3), 339-356, https://doi.org/10.1017/S0261143005000553.

Gardstrom, S. C. (2007). Music therapy improvisation for groups: Essential leadership competencies. Gilsum, NH: Barcelona Publishers.

Gopinath, S., \& Stanyek, J. (2014). The mobilization of performance: An introduction to the aesthetics of mobile music. The Oxford handbook of mobile music studies, 2, 1-39, https://doi.org/10.1093/oxfordhb/9780199913657.013.001.

Gustafson, R. (2008). Drifters and the dancing mad: The public school music curriculum and the fabrication of boundaries for participation. Curriculum Inquiry, 38(3), 267-297, https://doi.org/10.1111/j.1467-873X.2008.00409.x.

Hadley, S., \& Norris, M. S. (2016). Musical multicultural competency in music therapy: The first step. Music Therapy Perspectives, 34, 129-137, https://dx.doi.org/10.1093/mtp/miv045.

Hahna, N. D., Hadley, S., Miller, V. H., \& Bonaventura, M. (2012). Music technology usage in music therapy: A survey of practice. The Arts in Psychotherapy, 39(5), 456-464, https://doi.org/10.1016/j.aip.2012.08.001.

Hein, E. (2018). The Ethan Hein Blog. Retrieved fromhttp://www.ethanhein.com/wp/2018/ teaching-whiteness-in-music-class/.

Hiller, J., \& Gardstrom, S. (2018). The selection of music experiences in music therapy. Music Therapy Perspectives, 36, 79-86, https://doi.org/10.1093/mtp/miy001.

Hillyard, K. (2015). Music News. Retrieved from http://www.nme.com/news/music/variousartists-1151-1214849.

Holmes, T. (2012). Electronic and experimental music: Technology, music, and culture (4th ed.). New York, NY: Routledge.

Katz, M. (2012). Groove music: The art and culture of the hip-hop DJ. New York, NY: Oxford University Press.

Keyes, C. L. (1996). At the crossroads: Rap music and its African nexus. Ethnomusicology, 40(2), 223-248, https://doi.org/10.2307/852060.

Kim, S., \& Whitehead-Pleaux, A. (2015). Music therapy and cultural diversity. In B. L. Wheeler (Ed.), Music therapy handbook (pp. 51-63). London, England: The Guildford Press.

Kirn, P. (2011). Keyboard presents the evolution of electronic dance music. Milwaukee, WI: Backbeat Books.

Knight, A., \& Krout, R. (2016). Making sense of today's electronic music technology resources for music therapy. Music Therapy Perspectives, 35, 219-225, https://doi.org/10.1093/mtp/ miw025.

Knight, A., \& Lagasse, A. B. (2012). Re-connecting to music technology: Looking back and looking forward. Music Therapy Perspectives, 30, 188-195, https://doi.org/10.1093/mtp/ 30.2.188. 
Koza, J. E. (2009). Listening for whiteness: Hearing racial politics in undergraduate school music. In A. T. Regelski \& T. J. Gates (Eds.), Music education for changing times: Guiding visions for practice (pp. 85-97). New York, NY: Springer. https://doi.org/10.1007/ 978-90-481-2700-9_7.

Kreems, N., \& Junaini, H. (2016). The lost history of Singapore's secretly influential drum and bass scene. Retrieved from https://thump.vice.com/en_uk/article/d7jxeq/the-lost-historyof-singapores-secretly-influential-drum-and-bass-scene

Krout, R. E., \& Mason, M. (1988). Using computer and electronic music resources in clinical music therapy with behaviourally disordered students, 12 to 18 years old. Music Therapy Perspectives, 5, 114-118, https://doi.org/10.1007/978-90-481-2700-9_7.

Kubicek, L., Martino, L., \& Zigo, J. B. (2011). Using music technology in music therapy with populations across the life span in medical and educational programs. Music and Medicine, 3(3), 146-153, https://doi.org/10.1177/1943862111403005.

Leight, E. (2016). 8 ways the 808 Drum machine changed pop music. Rolling Stone, Retrieved from https://www.rollingstone.com/music/news/8-ways-the-808-drum-machine-changedpop-music-w453714.

Lightstone, A. (2012). The importance of hip-hop for music therapists. In S. Hadley \& G. Yancy (Eds.), Therapeutic uses of rap and hip-hop (pp. 39-56). New York, NY: Routledge.

Linn, R. (1994). MPC3000 MIDI production center: Software version 3.0 operator's manual. Akai Electric Co., LTD.

MacDonald, S., \& Viega, M. (2012). Hear our voices: A music therapy songwriting program and the message of the Little Saints through the medium of rap. In S. Hadley \& G. Yancy (Eds.), Therapeutic uses of rap and hip-hop (pp. 153-171). New York, NY: Routledge.

Magee, W. (2006). Electronic technologies in clinical music therapy: A survey of practice and attitudes. Technology and Disability, 18(3), 139-146.

Magee, W. (2014). Music technology in therapeutic and health settings. London, UK: Jessica Kingsley Publishers.

Magee, W., \& Burland, K. (2008). Using Electronic music technologies in music therapy: Opportunities, limitations and clinical indicators. British Journal of Music Therapy, 22(1), 3-15, https://dx.doi.org/doi:10.1177/135945750802200102.

Marr, J. T. (2016). A tale of electronic bass music \& the elusive composition copyright: A discussion of the gap in copyright protection for bass music producers. Virginia Sports and Entertainment Law Journal, 16(12), 244-266.

Martino, L., \& Bertolami, M. (2014). Using music technology with children and adolescents with visual impairments and additional disabilities. In W. Magee (Ed.), Music technology in therapeutic and health settings (pp. 165-179). London, UK: Jessica Kingsley publishers.

McLeod, K. (2001). Genres, subgenres, sub-subgenres and more: Musical and social differentiation within electronic/dance music communities. Journal of Popular Music Studies, 13(1), 59-75, https://doi.org/10.1111/j.1533-1598.2001.tb00013.x.

Nagler, J. C., \& Lee, M. H. (1987). Use of microcomputers in the music therapy process of a postrival encephalitic musician. Medical Problems of Performing Artists, 2(2), 72-74.

Neill, B. (2002). Pleasure beats: Rhythm and the aesthetics of current electronic music. Leonardo Music Journal, 12, 3-6, https://doi.org/10.1162/096112102762295052.

Perry, I. (2004). Prophets of the hood: Politics and poetics in hip hop. Durham, NC: Duke University Press. https://doi.org/10.1215/9780822386155.

Ramsey, D. W. (2014). Foreward. In W. Magee (Ed.), Music technology in therapeutic and health settings (pp. 11-14). London, UK: Jessica Kingsley publishers.

Richards, J. (2013). Beyond DIY in electronic music. Organised Sound, 18(3), 274-281, https://dx.doi.org/10.1017/S1355771813000241.

Roberts, M. (2006). "I want to play and sing my story": Home-based songwriting for bereaved children and adolescents. The Australian Journal of Music Therapy, 17, 18-34. 
Rodriquez, J. (2006). Color-blind ideology and the cultural appropriation of Hip-Hop. Journal of Contemporary Ethnography, 35(6), 645-668, https://dx.doi.org/doi:10.1177/ 0891241606286997.

Rose, T. (1994). Black noise: Rap music and Black culture in contemporary America. London, UK: Wesleyan Univesrity Press.

Sadovnik, N. (2014). The birth of a therapeutic recording studio: Addressing the needs of the hip-hop generation on an adult inpatient psychiatric unit. In W. Magee (Ed.), Music technology in therapeutic and health settings (pp. 247-262). London, UK: Jessica Kingsley Publishers.

Said, A. (2016). The BeatTips manual: The art of beatmaking, the hip hop/rap music tradition, and the common composer (6th ed.). Brooklyn, NY: Superchamp Books.

Schloss, J. G. (2014). Making beats: The art of sample-based hip-hop. Middletown, Connecticut: Wesleyan University Press.

Scrine, E. (2016). Enhancing social connectedness or stabilising oppression: Is Participation in music free from gendered subjectivity? Voices: A World Forum for Music Therapy, 16(2), https://dx.doi.org/10.15845/voices.v16i2.881.

Speers, L. (2017). Hip-hop authenticity and the London scene: Living out authenticity in popular music. Abingdon, Oxon: Taylor \& Francis.

Stadnicki, D. A. (2017). Play like Jay: Pedagogies of drum kit performance after J Dilla. Journal of Popular Music Education, 1(3), 253-280, https://doi.org/10.1386/jpme.1.3.253_1.

Taylor, T. D. (2014). Strange sounds: Music, technology and culture. New York, NY: Routledge.

Théberge, P. (2001). 'Plugged in': Technology and popular music. In S. Frith, W. Straw, \& J. Street (Eds.), The Cambridge companion to pop and rock (pp. 3-25). Cambridge, UK: Cambridge University Press. https://doi.org/10.1017/CCOL9780521553698.003.

Thompson, P. (2012). An empirical study into the learning practices and enculturation of DJs, turntablists, hip hop and dance music producers. Journal of Music, Technology \& Education, 5(1), 43-58, https://doi.org/10.1386/jmte.5.1.43_1.

Viega, M. (2014). Listening in the ambient mode: Implications for music therapy practice and theory. Voices: A World Forum for Music Therapy, 14(2), http://dx.doi.org/10.15845/ voices.v14i2.778.

Viega, M. (2016). Exploring the discourse in Hip Hop and implications for music therapy practice. Music Therapy Perspectives, 34, 138-146, https://dx.doi.org/10.1093/mtp/miv035.

Weissberger, A. (2014). GarageBand as a digital co-facilitator: Creating and capturing moments with adults and elderly with chronic health conditions. In W. Magee (Ed.), Music technology in therapeutic and health settings (pp. 279-291). London, UK: Jessica Kingsley publishers.

Williams, D. A. (2011). The elephant in the room. Music Educators Journal, 98(1), 51-57, https://dx.doi.org/10.1177/0027432111415538. 